\title{
On Tocqueville's Political Thought a General Review
}

\author{
Bengucan Findik \\ Agri Ibrahim Cecen University, \\ Department of Political Science and Public Administration, Agri, Turkey
}

\begin{abstract}
Alexis De Tocqueville is an intellectual who lived in a 19th century. There are two important works in his academic literature that are still up to date: 'Democracy in America' and 'Ancient Regime and Revolution'. Generally, 'Democracy in America' examines the political systems of America and France in that day comparatively. In his work titled 'Ancient Regime and Revolution', Tocqueville examines the issue of what changed and even if it changed in France after the Revolution. The comparative method used by Tocqueville makes him one of the pioneers of comparative politics. His debates about democracy enabled him to be described as a democracy theorist.

What makes Tocqueville important today; it is the consepts of freedom, centrality problem and tyranny of the masses that he has included in the discussions of democracy. These three focal points are still considered as a benchmark in discussions about how democratic democracies are today. The objective comments of Tocqueville on the French Revolution are valuable in that it is one of the first criticisms of the Revolution within France. Tocqueville compared the French Revolution with previous religious revolutions and analyzed the changes created by the revolution from a critical perspective.
\end{abstract}

Keywords: Tocqueville, Democracy in America, Ancient Regime and Revolution

DOI: $10.7176 / \mathrm{JSTR} / 6-08-12$

\section{Tocqueville'nin Siyasal Düşüncesi Üzerine Genel Bir Inceleme}

\begin{abstract}
Özet
Alexis De Tocqueville bir 19. yüzyıl düşünürüdür. Akademik yazında hala güncelliğini korumakta olan iki önemli eseri vardır: 'Amerika'da Demokrasi' ve 'Eski Rejim ve Devrim'. Genel olarak söylemek gerekirse; 'Amerika'da Demokrasi' Amerika ve Fransa'nın o günkü siyasi sistemlerini karşılaştırmalı olarak incelemektedir. 'Eski Rejim ve Devrim' isimli eserinde ise Tocqueville, Devrim sonrası Fransa'da neyin ne kadar değiştiği ve hatta değişip değişmediği konusunu irdelemektedir. Tocqueville'nin kullanmış olduğu karşılaştırmalı metot onu karşılaştırmalı siyasetin öncülerinden biri konumuna getirmektedir. Demokrasiyle ilgili yaptı̆̆ı tartışmalar ise onun bir demokrasi kuramcısı olarak tanımlanmasını sağlamıştır.

Tocqueville'yi güncel kılan şey; onun demokrasi tartışmalarında yer vermiş olduğu özgürlük, merkezilik sorunu ve yığınların tiranlığıdır. Bu üç odak noktası, günümüzde dahi demokrasilerin ne kadar demokratik olduğuna dair tartışmalarda bir kıstas olarak kabul edilmektedir. Tocqueville'nin Fransız Devrimi hakkındaki objektif yorumları ise Devrime Fransa içinden yapılmış ilk eleştirilerden biri olması bakımından değerlidir. Tocqueville, Fransız Devrimi’ni daha önceki dini devrimlerle kıyaslamış ve devrimin yaratığı değişimleri eleştirel bir bakış açısıyla incelemiştir.
\end{abstract}

Anahtar Kelimeler: Tocqueville, Amerika’da Demokrasi, Eski Rejim ve Devrim

\section{Giriș}

Alexis De Tocqueville 1805 yılında Paris'te aristokrat bir ailede dünyaya gelmiştir. Felsefesinin temelini ilk bakışta demokrasi kavramının oluşturduğunu düşünebiliriz. Çalışmalarının büyük çoğunluğunda demokrasinin ne olduğunu, nasıl anlaşılması gerektiğini, demokratik toplumlarda olan ve olmayan özellikleri buluruz. Doğal olarak Tocqueville, bir demokrasi kuramcısı olarak tanımlanabilir. Bununla 
beraber, Tocqueville'nin odak noktası Fransa'dır. Öyle ki yazdığı iki büyük yapıtta da -Amerika'da Demokrasi ve Eski Rejim ve Devrim- temel araştırma nesnesi Fransa'dır. 'Amerika'da Demokrasi'de Tocqueville; Fransa'nın o dönemki siyasal yapısıyla Amerika'nın siyasal yapısını karşılaştırarak, Fransa ile ilgili çıkarımlar yapmakta, öngörüde bulunmakta ve tavsiyeler vermektedir. 'Eski Rejim ve Devrim'de ise, devrim öncesi Fransa ile Devrim sonrası Fransa'yı karşılaştırarak, devrimin neyi ne kadar değiştirdiğini ve hatta değiştirip değiştirmediğini irdelemektedir. Tocqueville bir sosyolog değildir ama sosyolojik bir düşünceyi kullanmaktadır. İki yapıtında da kullanmış olduğu karşılaştırma metodu, kendisini karşılaştırmalı siyasetin öncüleri arasına sokmuştur.

Tocqueville; Amerika'nın neden liberal olduğu ve Fransa'da bu liberalliğin neden olmadığı sorusuyla yola çıkmıştır. Amerika ve Fransa'daki din kurumunun rolünü sorgulayarak çıkarımlarda bulunmuştur. Fırsat eşitliğini kavramını irdelemiş, merkeziyetçilik ve ademi merkeziyetçilik üzerine düşünmüştür. Marx'dan farklı da olsa sınıf kavramını kullanmıştır. Yığınların tiranlığını bir tehlike olarak tanımlamıştır. Tocqueville'nin yığınların tiranlı̆̆ı tespiti, bugünün dünyasında da güncelliğini korumaktadır. Tocqueville ilerlemeci bir tarih anlayışına sahip değildir ancak ilerleme düşüncesinin de içerisindedir. Tocqueville'in Fransa için bir değişim tahlili vardır, tüm dünyada gözlemlenen değişimin adı ona göre demokrasidir ve dalgalar halinde gelişen dinamik bir yapısı vardır.

Tocqueville'nin 'Amerika'da Demokrasi' ile 'Eski Rejim ve Devrim' kitaplarını incelediğimizde, düşünürün sağduyusuna ve analiz yeteneğine hayran kalabiliriz. Dönem şartlarında devrim karşıtı ya da eskiye dönüş taraftarı olmadan devrimi eleştirebilmesi ve evrimin ateşli bir savunucusu olmadığı halde demokratik ideallere bağlı olması; demokrasinin nispeten sancısız ve doğru temeller üzerine kurularak benimsendiği Amerika'yı inceleyerek kendi ülkesiyle ilgili değerlendirmeler yapması, bu sağduyuyu hissetmemizi sağlar. Amerikan toplumu ve Fransız Devrimi hakkındaki analizleri ise isabetli ve bilimin kabul ettiği analizlerdir.

Tocqueville'ye göre demokrasi nedir diye sorulacak olursa; demokrasi her şeyden önce toplumsal bir olgu ve koşulların eşitliğidir ${ }^{1}$. Bu olgu vatandaşların kamu işlerine katılımı ve halk egemenliğiyle şekillenir. Aron'a göre Tocqueville'nin özgürlükten daha çok sevdiği bir kelime yoktur. Özgürlük her şeyden önce yasaların koruması altında herkesin güvenliğidir. Özgür olmak güçlülerin ya da otoritenin keyfi baskılarıyla karşı karşıya kalmamaktır. Keyfiliğge karşı bu koruma azınlıkları da kapsamalı ve hatta insanların haklarını kötüye kullanmalarını engellemelidir ${ }^{2}$.

Tocqueville'ye göre Amerika'da demokrasiyi şekillendiren etmenlerin başında New England göçmenlerinin benimsediği Prütanizm vardır. Prütanizm, sadece dini bir öğreti değil aynı zamanda demokratik ve cumhuriyetçi teorilerle yüklü siyasi bir öğretidir ${ }^{3}$. New England'da kanunlar, ilgilenenlerin katılıp serbestçe oyladığı bir süreç sonunda oluşuyordu. Bu kanunlar arasında evli olmayanların cinsel ilişkiye girmeleri, belli bir miktardan sonra alkolün yasaklanması, kiliseye gitmeyenlerin cezalandırılması gibi demokrasiyle bağdaşmayacak kanunlar olsa da; çağdaş anayasaların temelini oluşturan genel prensipler de aynı New Englandlılar tarafından kanunlaştırılmıştır. Halkın kamu işlerine dahil olması, vergilerin oylanarak belirlenmesi, idari güç sahiplerinin sorumluluğu, kişi özgürlükleri, jüri tarafından yargılanma bu kanunlara örnektir ${ }^{4}$.

New England kanunlarında Amerikan özgürlüğünün temeli olan yerel idarelerin gelişmesinin de özünü bulmak mümkündür. Amerika'da önce kasabalar, şehirler sonra eyaletler ve en sonunda da Birleşik Devlet örgütlenmesi gerçekleşmiştir. Böylece siyasal örgütlenme tarzı tabandan tavana doğru olmuştur. İlçe düzeyindeki yerel birimlerin bağımsızlığı, hakların ve görevlerin birbirine tutunduğu özü oluşturmuş; bu ortam da tam demokratik ve cumhuriyetçi siyasal hayata imkan sağlamıştır.

Amerika'daki ademi merkeziyetçiliğin ve Fransa'daki merkeziyetçiliğin tarihsel sebepleri vardır. Amerika'daki yönetimler daha önce medeni dünya tarafindan etkilenmemiş bir toprak üzerinde ve eski bir uygarlığın araç ve bilgilerini kullanan göçmenlerce kurulmuştur. Yeni düzen, kuruluşlarından itibaren düşmansız olmuştur. Rakip komşularla çevrili olan Fransızlarda ise dış güvenlik kaygısının her şeyden önemli olması devlete büyük ayrıcalıkların verilmesine sebep olmuştur. Devrimden önce de merkeziyetçi olan Fransa, devrimden sonra da merkeziyetçi olmaya devam etmiştir, Aron'a göre bu durum demokrasilerdeki merkezileşme eğiliminin de bir sonucu olarak görülebilir ${ }^{5}$.

Herkesin kendi eseri olarak gördüğü bir demokraside vatandaşlar Tocqueville’ye göre; hükümetlere herhangi bir kutsallık atfetmeden, duygusal olarak değil, ikna olukları için bağlılık duyacaklardır. Kendi gerçek çıkarlarıyla tanışan halk, toplumun sunduklarından yararlanmak için üzerlerine düşeni yapma

\footnotetext{
${ }^{1}$ Raymond Aron, Sosyolojik Düşüncenin Evreleri, Kırmızı Yayınevi, 2014, İstanbul , s. 447

${ }^{2}$ Aron, s.448

${ }^{3}$ Alexis De Tocqueville, Amerika'da Demokrasi, Yetkin Yayınevi, 1994, Ankara , 1994, s. 35

${ }^{4}$ Tocqueville, 1994, s. 39

${ }^{5}$ Aron, s. 452 
gerekliliğini de anlayacaktır. Asillerin bireysel nüfuslarının yerini gönüllü dernekler ve bağımsız kurumlar alacak; böylece toplum hem anarşiden hem de baskıdan kurtulmuș olacaktır. ${ }^{6}$

Tocqueville, merkezileşme konusunu siyasal ve yönetsel merkezilik olarak ikiye ayırmıştır. Siyasal merkezilik olan birinci tür; savunma, dış politika, genel yasalar gibi ulusun bütününü ilgilendiren uygulamaları kapsamaktadır. Yönetsel merkezilik ise daha çok yereli ilgilendiren; okul, alt yapı çalışmaları, yerel vergiler ve yerel işlerin yürütülmesiyle ilgili uygulamaları kapsamaktadır. Tocqueville ulusun bütününü ilgilendiren siyasal merkeziliği yararlı bulurken, yönetsel merkeziliği yanlış ve tehlikeli bulmaktadır $^{7}$. Devletin güvenliğini sağlayabilecek kadar güçlü, yasaların yerel ortamlara uygun olabilmesi için de yeterince küçük olması gerekmektedir. Bu büyük ve küçük devlet uyumu yalnızca federal ya da konfederal anayasalarla mümkündür. Tocqueville'e göre de Amerikan anayasasının ilk onuru budur ${ }^{8}$.

Değişen egemenlik anlayışılyla beraber krala ait olan üstün, mutlak, sınırsız hükmetme hakkı herhangi bir değişikliğe uğramadan milletin eline verilerek 'milli irade' adını almış ${ }^{9}$ ve bu kavram her dönemde düzenbazlar ve zorbalar tarafindan kullanılmıştır ${ }^{10}$. Tocqueville'e göre demokratik hükümetler halkın tutkusal coşkularına kendini bırakmamalıdır ${ }^{11}$.

Aristo gibi Tocqueville de demokrasi karşısındaki büyük bir tehlike olarak yığınların tiranlığını görmektedir. Yukarda da bahsettiğimiz gibi her demokrasi merkeziyetçiliğe eğimlidir ve sonuçta bir kişinin ya da yığınların tiranlığına, istibdadına dönüşebilir. Tocqueville'ye göre demokrasi, sürekli olarak çoğunluğun zorba yönetimi tehlikesiyle karşı karşıyadır. Her demokratik rejim çoğunluğun haklı olduğunu iddia edebilir ve çoğunluğun haklarını kötüye kullanıp azınlıkları ezmesini önlemek güç hale gelebilir ${ }^{12}$. Yığınların tiranlı̆̆ tehlikesinin Amerika'da olmamasının nedenleri halkın yerel düzeydeki sorunlarla birebir uğraşarak demokrasi kültürünü geliştirmesi ve hükümetlerin son derece sınırlı olmasıdır. Amerika'da gücün merkezi toplumdur. Yöneticiler güçlerinin kaynağını asla unutmazlar ve hükümetin payı o kadar sınılıdır ki, ulusun kendi kendini yönettiği bile söylenebilirr ${ }^{13}$.

Tocqueville; demokrasilerin merkezileşme eğiliminde olduğunu kabul eder ve devrim sonrası Fransa'nın XIV. Louis zamanındaki Fransa'dan daha merkeziyetçi olduğunu söyler. Amerikalılar bu merkeziyetçilik sorununu iktidarı dağıtarak çözmüşlerdir. Makamı güçlü, memuru korkulmayacak biri yapan da, yetkilerin bölünmesidir ${ }^{14}$.

Eski Rejim ve Devrim adlı eserinde Tocqueville; devrimin eskiyi bozan ve yenileştiren olağanüstü bir etkisinin olup olmadığını sorgulamaktadır. Tocqueville, devrimin oluşmasında büyük önemi olan XVIII. Yüzyıl düşünürlerinin, dine karşı bir şiddete kapılmış olduklarını söyler. Ancak düşünürlerin ve dönem felsefesinin asıl saldırdığı şey; bir dini öğreti olarak Hristiyanlık değil, siyasal bir kurum olarak kilise idi. Papazlar dini işlerle uğraştığı için değil, toprak sahibi, yönetici ve senyör oldukları için hedef haline gelmişlerdir. Kilise de kurulacak yeni düzende var olamayacağı için değil; eski toplum içinde en ayrıcalıklı ve güçlü yeri işgal ettiği için tehlikeli bulunmuştur. Yani demokratik toplumların direkt olarak dine düşman olduklarını söylemek Tocqueville'ye göre yanlıştır. Tocqueville kendisi de dindar bir Hristiyan olduğu için böyle bir çıkarım yapma zorunluluğu hissetmiş olabilir ancak devrimin anarşik kimliğini de kabul etmiştir. Tocqueville'ye göre Fransız Devrimi'nin hedefi yalnızca eski bir hükümet biçimini değiştirmek değil, eski toplum düzenini de yıkmak olduğundan; devrim aynı anda bütün yerleşik güçlere saldırmak, bilinen bütün nüfuzları ortadan kaldırmak, gelenekleri silmek, örf ve adetleri yenilemek ve o güne kadar saygının ve itaatin temelleri olan bütün fikirleri zihinlerden kazımak zorunda kalmıştır. Devrimin Tocqueville'ye göre anarşik kimliği de buradan kaynaklanmaktadır.

Tocqueville'ye göre, Fransız Devrimi bu dünya karşısında, bütünüyle öteki dünyayı hedefleyen dinsel devrimlerle aynı tarzda davranmıştır. Yurttaş kavramını bütün tikel toplumların dışında, soyut bir biçimde, tıpkı dinlerin de insanları ülke ve zamandan bağımsız olarak düşündüğ̈̈ gibi düşünmüştür. Yalnızca Fransız yurttaşının tikel hakkının ne olduğunu araştırmamış; insanların siyasal alandaki genel ödevlerinin ve haklarının neler olduklarını da araştırmıştır. Devrim, Fransa'nın yeni baştan yapılandırılmasından ziyade, insan türünün yeniden canlandırılmasına eğilimli göründüğünden, o güne kadar en şiddetli siyasal devrimlerin asla yaratamamış oldukları bir tutkuyu alevlendirmiştir. Bu yolla, dinsel devrim havasına bürünebilmiş, bütün yeryüzünü askerleriyle, havarileriyle ve şehitleriyle istila

\footnotetext{
${ }^{6}$ Tocqueville, 1994, s. 24

${ }^{7}$ Mehmet Yetiş, "Tocqueville ve Merkeziyetçilik Sorunu", Ankara SBF Dergisi, c.61 sayı 3, s.283, 2006, Ankara

${ }^{8}$ Aron, s. 171

${ }^{9}$ Münci Kapani, Politika Bilimine Giriș, Bilgi Yayınevi, 2006, Ankara, s.79

${ }^{10}$ Tocqueville, 1994, s.49

${ }^{11}$ Aron, s. 172

${ }^{12}$ Aron, s. 176

${ }^{13}$ Tocqueville, 1994, s.50

${ }^{14}$ Tocqueville, 1994, s. 54
} 
eden bir din haline gelmiştir. Bu yönüyle Fransız Devrimi’nin dinsel devrimlerden farkı yoktur ancak devrimin dinsel inançları yıkmak için yapılmış olduğunu söylemek de Tocqueville'ye göre yanlış olacaktır. Tocqueville'ye göre devrim toplumsal ve siyasal bir devrimdir, düzensizliği istikrarlaştırma veya anarşiyi yöntemleştirme gibi bir amacı da yoktur. Devrim daha çok kamusal aklın gücünü ve haklarını genişletmeye eğilim göstermiştir. Fransız Devrimi’nin en büyük etkisi aristokratik ve feodal kurumlardan kaynaklanan her şeyi köktenci şekilde yok etmesidir. Bu köktenci yok edicilik devrimi olduğundan daha büyük göstermiş ve devrim, varsayıldığından daha az yenilik getirmiştir.

\section{Sonuç Yerine}

Tocqueville; demokrasi tartışmasını Amerika ve Fransa örnekleri üzerinden yürütmüştür. Tocqueville, bir ön kabul olarak Amerika'da demokrasinin varlığını görmüş, Fransa'da nelerin eksik olduğunu aramış ve bulduğu eksiklikleri de demokratik kıstaslar olarak ortaya koymuştur. Tocqueville'nin ilk kıstası özgürlüktür. Özgürlük ise en yalın ifade ile yasalara bağlı bir yönetimin varlığ ile keyfi iradenin olmaması, hakların ve yükümlülüklerin belirlenerek, çoğunluğun azınlığı istismar edememesidir. Tocqueville; tarihsel ve coğrafi şartların etkisini kabul etmekle beraber, ikinci kıstas olarak merkez-yerel ilişkisini görmektedir. Merkez karşısında özerk bir güce sahip olan yerel birimler; hem daha çok insanın yönetime katılması bakımından, hem de devlet otoritesini korkulan değil sahiplenilen bir olgu olarak görülmesine sebep olacağından; Tocqueville'ye göre katı merkeziyetçi yönetimlere göre daha demokratiktir. Tocqueville'nin üçüncü demokrasi kıstası ise yığınların tiranlığı olasılığının önüne geçilmesidir ve bu konu da aslında merkez-yerel ilişkisi ile bağlantılıdır. Halkın yerel sorunlarla birebir uğraştı̆g 1 bir siyasi ortamda Tocqueville'ye göre demokrasi kültürü de gelişecek, bu sayede yığınların tiranlığ 1 tehdidi de ortadan kalkacaktır.

Tocqueville; devrim savunuculuğu yapmadan devrimi inceleme ve eleştirme cesaretini gösteren ilk Fransız düşünürlerden biridir. Tocqueville; Fransız Devrimi esnasında din ve kilise düşmanlığının birbirine karıştığını ve devrimin yıkmayı hedeflediği asıl şeyin bir kurum olarak kilise olduğunu tespit etmiştir. Kilise feodal toplumun en üst basamaklarında olması ve ayrıcalıklı yapısı sebebiyle yok edilmek istenmiştir. Fransız Devriminin ve demokratik toplumların din kavramına düşman oldukları konusu Tocqueville'ye göre yanlıştır.

Tocqueville, Fransız Devrimi’ni dinsel devrimlere benzetmiş ve onun ilahi bir görünüme girme çabasını da ortaya koymuştur. Tocqueville'nin bu tespiti; kendisinden sonraki akademik yazında sıkça karşılaşılan ideolojilerin sivil dinler olarak tanımlanmasının bir öncülü olarak kabul edilebilir. Fransız Devrimi; yurttaşı bireyden aşkın, zaman ve mekanın dışında soyut bir kavram olarak ele alarak ve ulusal değil küresel etkiler hedefleyerek, adeta bir din görünümüne bürünmüştür. Tocqueville’ye göre öz olarak dini devrimlerden farkı olmayan bu durum; Fransız Devrimi’nin şiddetli yıkıcılığından dolayı yeni bir olguymuş gibi algılanmasına ve olduğundan yüce gözükmesine sebep olmuştur.

\section{KAYNAKÇA}

ARON, Raymond; Sosyolojik Düşüncenin Evreleri, Kırmızı Yayınevi, 2014, İstanbul

KAPANI, Münci; Politika Bilimine Giriş, Bilgi Yayınevi, 2006, Ankara

TOCQUEVİLLE ,Alexis De; Amerika'da Demokrasi, Yetkin Yayınevi, 1994, Ankara

TOCQUEVİLLE, Alexis De; Eski Rejim ve Devrim, s.45 Kesit Yayıncılık, 1995, İstanbul

YETIŞ, Mehmet ; "Tocqueville ve Merkeziyetçilik Sorunu", Ankara SBF Dergisi, c.61 sayı 3, 2006, Ankara 